\title{
Non-contiguous finished genome sequence and description of Bacillus massilioanorexius sp. nov.
}

\author{
Ajay Kumar Mishra ${ }^{1}$, Anne Pfleiderer $^{1 \dagger}$, Jean-Christophe Lagier ${ }^{1}$, Catherine Robert ${ }^{1}$, Didier \\ Raoult $^{1}$ and Pierre-Edouard Fournier ${ }^{1 *+}$ \\ ${ }^{1}$ Aix-Marseille Université, URMITE, Faculté de médecine, France \\ *Correspondence: pierre-edouard.fournier@univmed.fr
}

Keywords: Bacillus massilioanorexius, genome, culturomics, taxonogenomics

'These two authors contributed equally to this work

Bacillus massilioanorexius strain $\mathrm{AP}^{\top} \mathrm{sp}$. nov. is the type strain of $B$. massilioanorexius sp. nov., a new species within the genus Bacillus. This strain, whose genome is described here, was isolated from the fecal flora of a 21-year-old Caucasian French female suffering from a severe form of anorexia nervosa since the age of 12 years. B. massilioanorexius is a Grampositive aerobic bacillus. Here we describe the features of this organism, together with the complete genome sequence and annotation. The 4,616,135 bp long genome (one chromosome but no plasmid) contains 4,432 protein-coding and 87 RNA genes, including 8 rRNA genes.

\section{Introduction}

Bacillus massilioanorexius strain AP8T $(=$ CSUR P201 = DSM 26092) is the type strain of $B$. massilioanorexius sp. nov. This bacterium is a Gram-positive, non-spore-forming, aerobic and motile bacillus that was isolated from the stool of a 21-year-old Caucasian French female suffering from a severe form of anorexia nervosa since the age of 12 years and is part of a "culturomics" study aiming at cultivating all species within human feces individually [1-3]. This bacterium was one of the 11 new bacterial species isolated from this single stool sample [3].

The current classification of Bacteria and Archaea remains a subject of debate and currently relies on a combination of phenotypic and genotypic characteristics [4]. Genomic data has not yet been routinely incorporated into descriptions. However, as more than 6,000 bacterial genomes have been sequenced including 982 type strains $[5,6]$ and another 15,000 genomic projects are ongoing including 2,120 type strains $[5,6]$, we recently proposed to integrate genomic information in the description of new bacterial species [7-28].

The genus Bacillus (Cohn 1872) was created in 1872 [29]. It consists mainly of Gram-positive, motile, spore-forming bacteria classified within 251 species and 3 subspecies with validly pub- lished names [30]. Members of the genus Bacillus are ubiquitous bacteria isolated from various environments including soil, fresh and sea water and food. In humans, Bacillus species may be opportunists in immunocompromised patients [31] or pathogenic, such as B. anthracis [32] and B. cereus. However, in addition to these two species, various Bacillus species may be involved in a variety of aspecific human infections, including cutaneous, ocular, central nervous system or bone infections, pneumonia, endocarditis and bacteremia [33].

Here we present a summary classification and a set of features for $B$. massilioanorexius sp. nov. strain AP8 ${ }^{\mathrm{T}}$ (= CSUR P201 = DSM 26092), together with the description of the complete genomic sequence and its annotation. These characteristics support the circumscription of the species $B$. massilioanorexius.

\section{Classification and information}

A stool sample was collected from a 21-year-old Caucasian French female suffering from a severe restrictive form of anorexia nervosa since the age of 12 years. She was hospitalized in the nutrition unit of our hospital for recent aggravation of her medical condition. At the time of hospitalization, her weight and height was $27.7 \mathrm{~kg}$, and $1.63 \mathrm{~m}$ 
(BMI: $10.4 \mathrm{~kg} / \mathrm{m}^{2}$ ) respectively. The patient gave an informed and signed consent. This study and the assent procedure were approved by the Ethics Committee of the Institut Fédératif de Recherche IFR48, Faculty of Medicine, Marseille, France (agreement 09-022). The fecal specimen was preserved at $-80^{\circ} \mathrm{C}$ after collection. Strain AP8T (Table 1) was isolated in March 2012 by aerobic cultivation on Columbia agar (BioMerieux, Marcy l'Etoile, France) after one month of preincubation of the stool sample with addition of $5 \mathrm{ml}$ of sheep rumen in blood bottle culture. This strain exhibited a $97 \%$ nucleotide sequence similarity with B. simplex [34], the phylogenetically closest validated Bacillus species (Figure 1). This value was lower than the $98.7 \%$ 16S rRNA gene sequence threshold recommended by Stackebrandt and Ebers to delineate a new species without carrying out DNADNA hybridization [35].

Table 1. Classification and general features of Bacillus massilioanorexius strain $\mathrm{AP}^{\mathrm{T}}$

\begin{tabular}{|c|c|c|c|}
\hline MIGS ID & Property & Term & Evidence code $^{\mathrm{a}}$ \\
\hline & \multirow{8}{*}{ Current classification } & Domain Bacteria & TAS [36] \\
\hline & & Phylum Firmicutes & TAS [37-39] \\
\hline & & Class Bacilli & TAS $[40,41]$ \\
\hline & & Order Bacillales & TAS $[42,43]$ \\
\hline & & Family Bacillaceae & TAS $[42,44]$ \\
\hline & & Genus Bacillus & TAS $[29,42,45]$ \\
\hline & & Species Bacillus massilioanorexius & IDA \\
\hline & & Type strain $\mathrm{AP}^{\top}$ & IDA \\
\hline & Gram stain & Positive & IDA \\
\hline & Cell shape & Bacilli & IDA \\
\hline & Motility & Motile & IDA \\
\hline & Sporulation & Nonsporulating & IDA \\
\hline & Temperature range & Mesophile & IDA \\
\hline & Optimum temperature & $37^{\circ} \mathrm{C}$ & IDA \\
\hline MIGS-6.3 & Salinity & Unknown & IDA \\
\hline \multirow[t]{3}{*}{ MIGS-22 } & Oxygen requirement & Aerobic & IDA \\
\hline & Carbon source & Unknown & NAS \\
\hline & Energy source & Unknown & NAS \\
\hline MIGS-6 & Habitat & Human gut & IDA \\
\hline \multirow[t]{3}{*}{ MIGS-15 } & Biotic relationship & Free living & IDA \\
\hline & Pathogenicity & Unknown & \\
\hline & Biosafety level & 2 & \\
\hline MIGS-14 & Isolation & Human feces & \\
\hline MIGS-4 & Geographic location & France & IDA \\
\hline \multirow[t]{2}{*}{ MIGS-5 } & Sample collection time & August 2011 & IDA \\
\hline & Latitude & 43.296482 & IDA \\
\hline MIGS-4.1 & Longitude & 5.36978 & IDA \\
\hline MIGS-4.3 & Depth & Surface & IDA \\
\hline MIGS-4.4 & Altitude & $0 \mathrm{~m}$ above sea level & IDA \\
\hline
\end{tabular}

Evidence codes - IDA: Inferred from Direct Assay; TAS: Traceable Author Statement (i.e., a direct report exists in the literature); NAS: Non-traceable Author Statement (i.e., not directly observed for the living, isolated sample, but based on a generally accepted property for the species, or anecdotal evidence). These evidence codes are from the Gene Ontology project [46]. If the evidence is IDA, then the property was directly observed for a live isolate by one of the authors or an expert mentioned in the acknowledgements. 


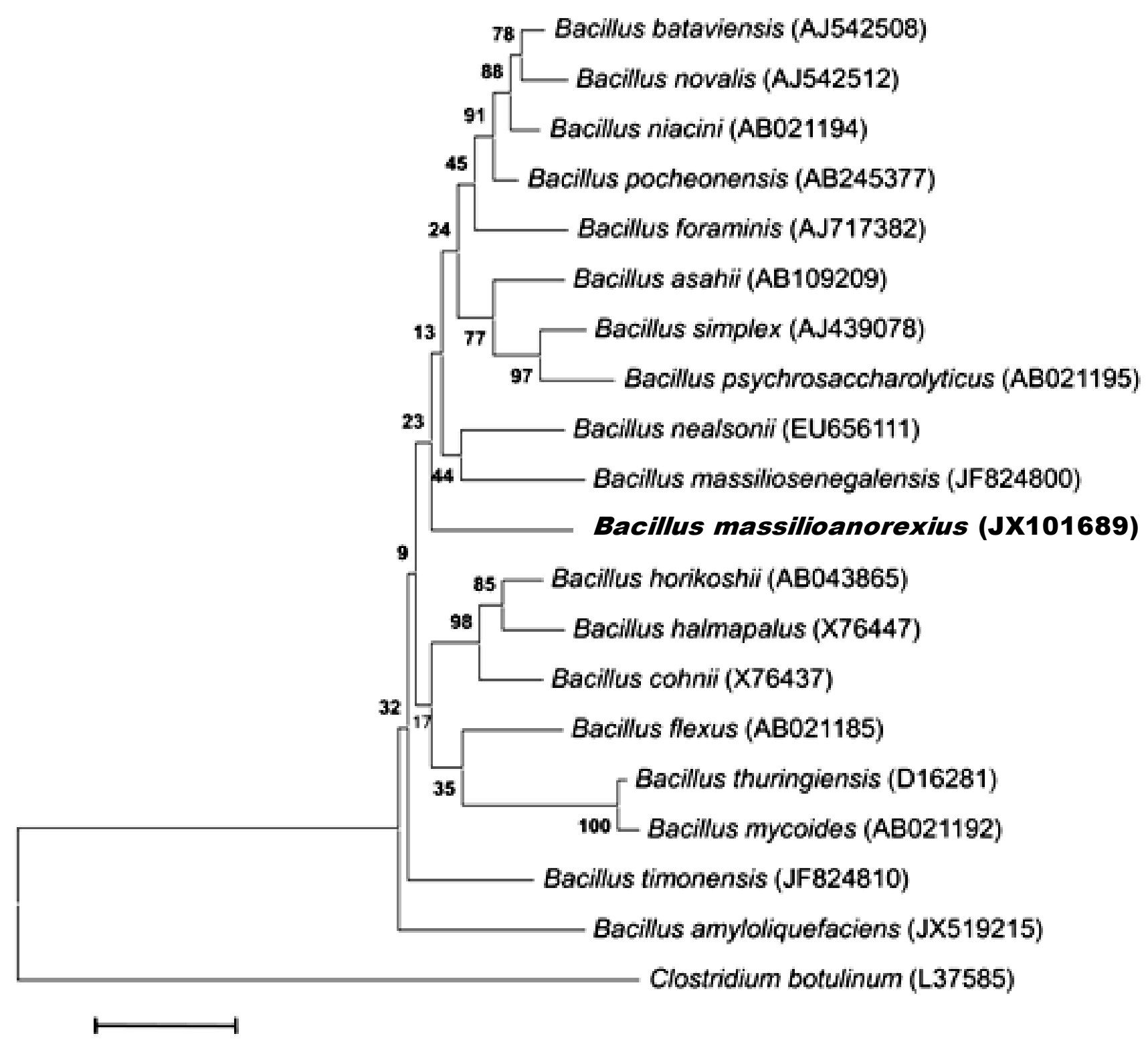

Figure 1. Phylogenetic tree highlighting the position of Bacillus massilioanorexius strain $A P 8^{\top}$ relative to a selection of type strains of validly published species of Bacillus genus. GenBank accession numbers are indicated in parentheses. Sequences were aligned using CLUSTALW, and phylogenetic inferences obtained using the maximum-likelihood method within MEGA program. Numbers at the nodes are percentages of bootstrap values obtained by repeating the analysis 500 times to generate a majority consensus tree. Clostridium botulinum was used as outgroup. The scale bar represents a $2 \%$ nucleotide sequence divergence.

Different growth temperatures $\left(25,30,37,45^{\circ} \mathrm{C}\right)$ were tested. Growth was observed between 25 and $45^{\circ} \mathrm{C}$, with optimal growth at $37^{\circ} \mathrm{C}$ after 24 hours of incubation. Colonies were $3 \mathrm{~mm}$ in diameter and $0.5 \mathrm{~mm}$ in thickness and gray in color with coarse appearance on blood-enriched Columbia agar. Growth of the strain was tested under anaerobic and microaerophilic conditions using GENbag anaer and GENbag microaer systems, respectively (BioMerieux), and under aerobic conditions, with or without $5 \% \mathrm{CO}_{2}$. Growth was obtained in all the above mentioned conditions except in anaerobic conditions, where weak growth was observed. Gram staining showed Gram-positive rods. The motility test was positive. Cells grown on agar are Gram-positive rods (Figure 2), have a mean diameter of $0.77 \mu \mathrm{m}$ and a mean length of $2.27 \mu \mathrm{m}$ in electron microscopy (Figure 3). 


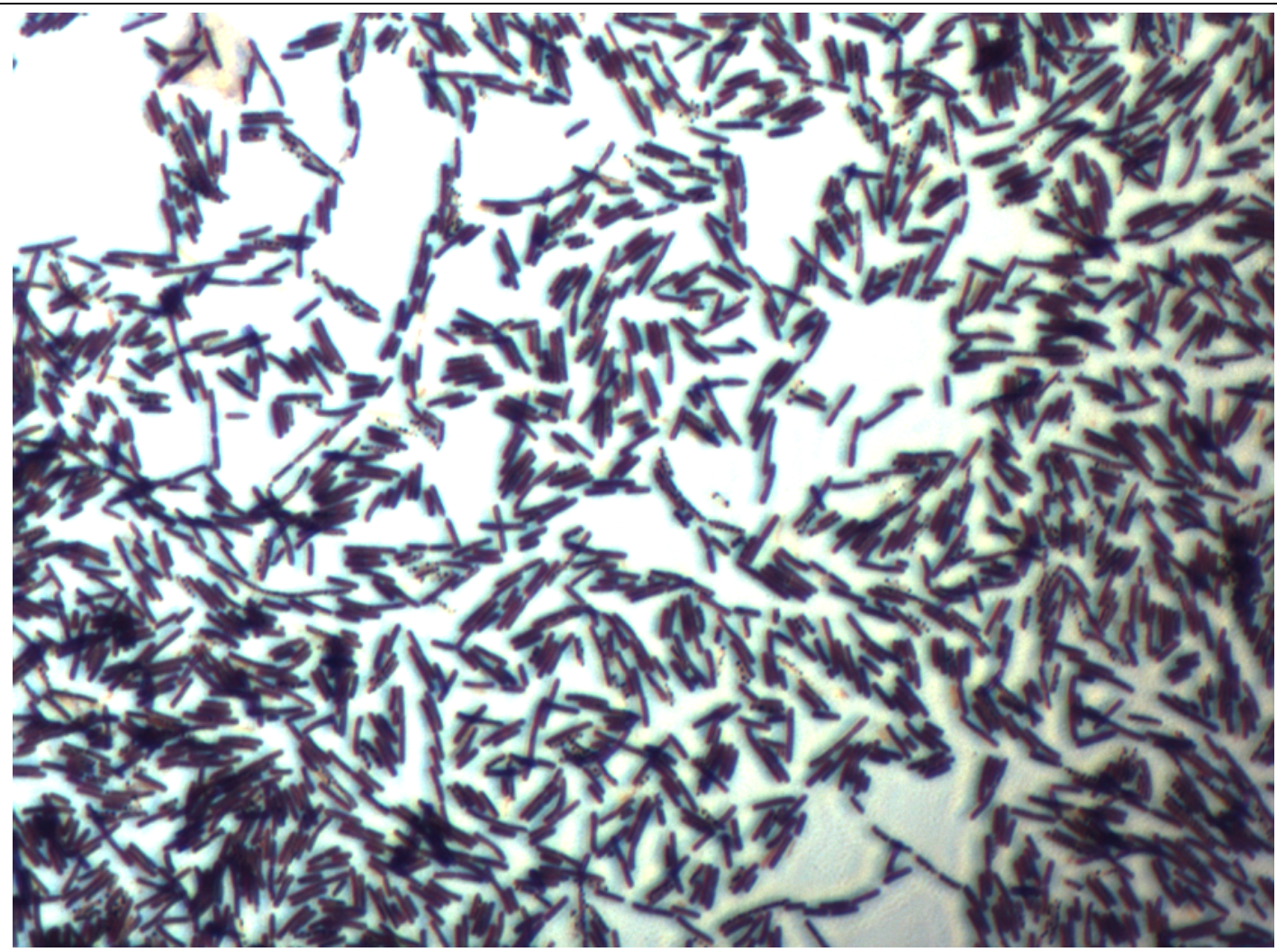

Figure 2. Gram staining of B. massilioanorexius strain $A P 8^{\top}$

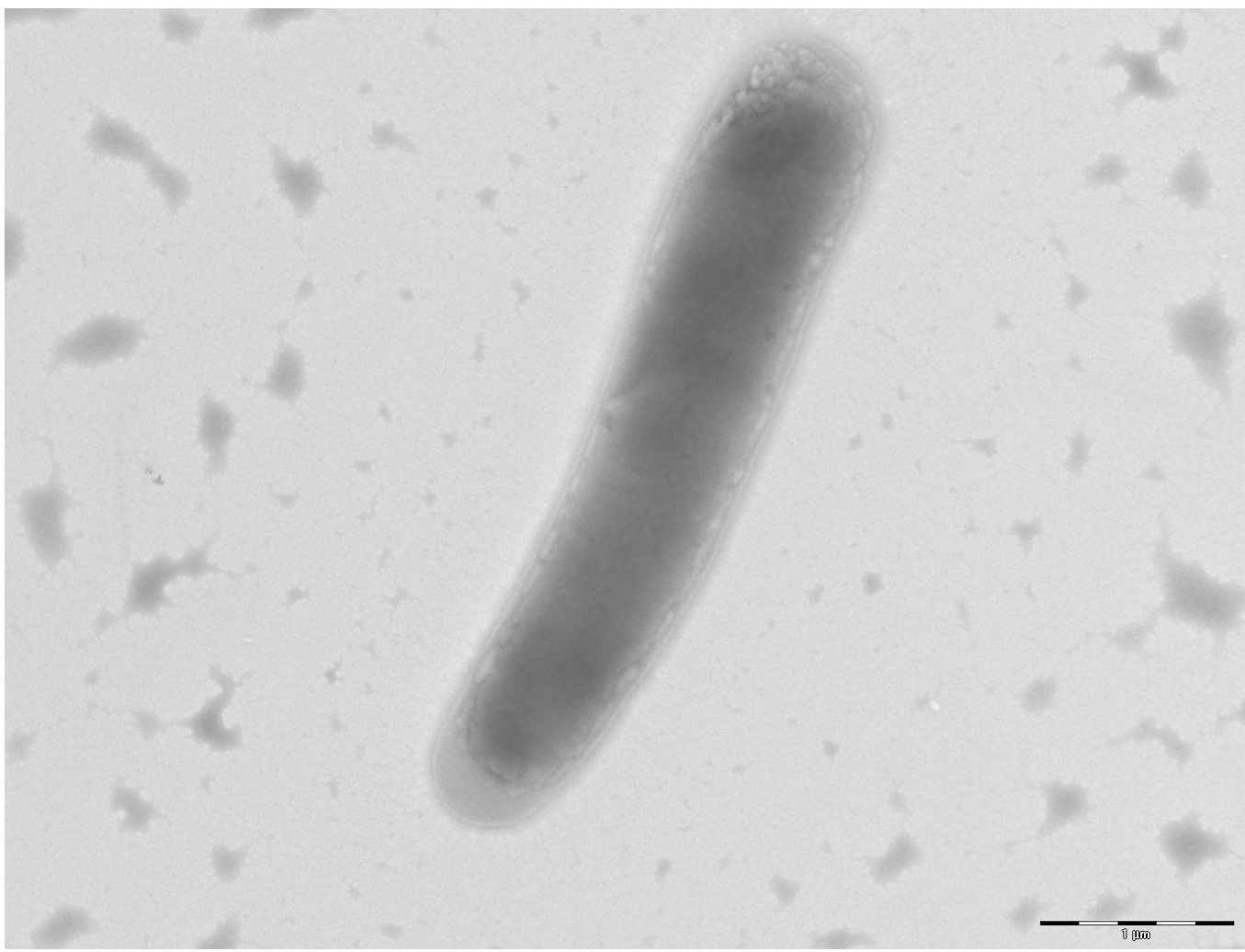

Figure 3. Transmission electron microscopy of $B$. massilioanorexius strain $\mathrm{AP}^{\top}{ }^{\top}$, using a Morgani 268D (Philips) at an operating voltage of $60 \mathrm{kV}$. The scale bar represents 900 $\mathrm{nm}$. 
Strain AP8T exhibited catalase and oxidase activity. Substrates oxidation and assimilation were examined with an API 50CH strip (BioMerieux) at the optimal growth temperature. Positive reactions were observed for D-glucose, D-fructose, Dsaccharose, ribose, mannose, mannitol and Dtrehalose and weak reactions were observed for L-rhamnose, esculine, salicine, D-cellobiose and gentiobiose. Using an API 20E strip (BioMerieux, Marcy l'Etoile), positive reactions were observed for tryptophane deaminase, acetoin and gelatinase production. Negative reactions were found for urease and indole production.

B. massilioanorexius is susceptible to amoxicillin, rifampicin, ciprofloxacin, gentamicin, doxycycline and vancomycin but resistant to trimethoprim/sulfamethoxazole and metronidazole. When compared with representative species from the genus Bacillus, B. massilioanorexius strain AP8T exhibited the phenotypic differences detailed in Table 2.

Table 2. Differential characteristics of Bacillus massilioanorexius strain AP8 ${ }^{\top}, B$. timonensis strain DSM 25372, B. amyloliquefaciens strain FZB42, B. massiliosenegalensis strain JC6 ${ }^{\top}$, B. mycoides strain DSM 2048 and B. thuringiensis strain BMB171

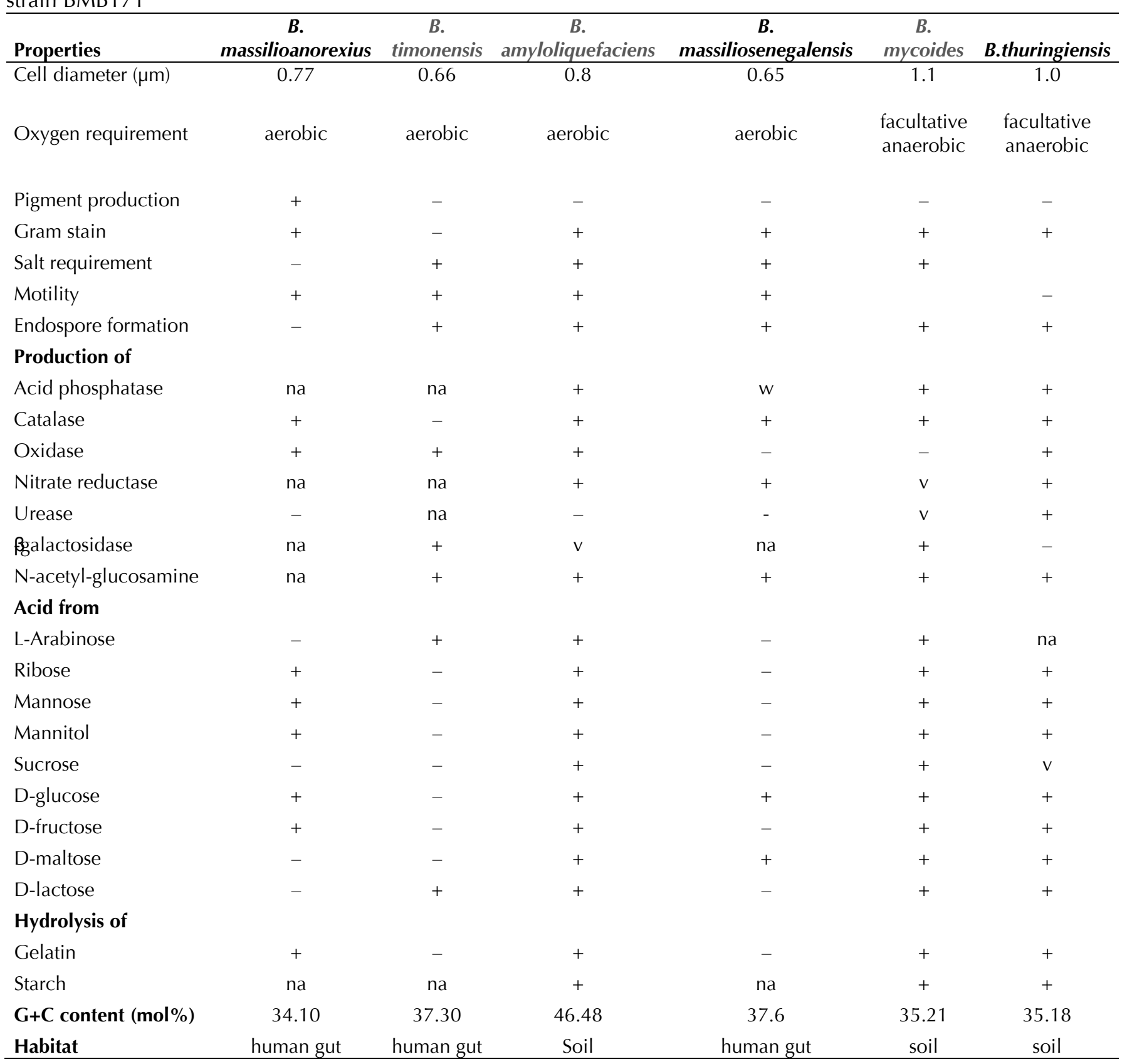

na = data not available; $w=$ weak, $v=$ variable reaction 
Matrix-assisted laser-desorption/ionization time-offlight (MALDI-TOF) MS protein analysis was carried out as previously described [47] using a Microflex spectrometer (Brüker Daltonics, Leipzig, Germany). Twelve individual colonies were deposited on a MTP 384 MALDI-TOF target plate (Brüker). The twelve AP8 $^{\mathrm{T}}$ spectra were imported into the MALDI BioTyper software (version 2.0, Brüker) and analyzed by standard pattern matching (with default parameter settings) against the main spectra of 3,769 bacteria, including 129 spectra from 98 validly named Bacillus species, used as reference data in the BioTyper database. A score enabled the presumptive identification and discrimination of the tested species from those in a database: a score $\geq 2$ with a validated species enabled the identification at the species level; and a score $<1.7$ did not enable any identification. For strain AP8T, no significant score was obtained, suggesting that our isolate was not a member of any known species (Figures 4 and 5).

\section{Genome sequencing information Genome project history}

The organism was selected for sequencing on the basis of its phylogenetic position and 16S rRNA similarity to other members of the Bacillus genus, and is part of a "culturomics" study of the human digestive flora aiming at isolating all bacterial species within human feces. It was the twenty-seventh genome of a Bacillus species and the first genome of
Bacillus massilioanorexius sp. nov. A summary of the project information is shown in Table 3. The Genbank accession number is CAPG00000000 and consists of 120 contigs. Table 3 shows the project information and its association with MIGS version 2.0 compliance [48].

\section{Growth conditions and DNA isolation}

Strain AP8T was grown aerobically in Columbia broth (BioMerieux, Marcy l'Etoile, France). Extraction of chromosomal DNA was performed by using $50 \mathrm{~mL}$ of $48-72 \mathrm{~h}$ culture of $B$. massilioanorexius, centrifuged at $4^{\circ} \mathrm{C}$ and $2000 \times \mathrm{g}$ for $20 \mathrm{~min}$. Resuspension of cell pellets was done in $1 \mathrm{~mL}$ Tris/EDTA/NaCl [10mM Tris/HCl (pH7.0), $10 \mathrm{mM}$ EDTA (pH8.0), and $300 \mathrm{mM} \mathrm{NaCl}]$ and recentrifugation was done under the same conditions. The pellets were resuspended in $200 \mu \mathrm{L}$ TE/lysozyme [25 mM Tris/HCl (pH8.0), $10 \mathrm{mM}$ EDTA (pH8.0), $10 \mathrm{mM} \mathrm{NaCl}$, and $10 \mathrm{mg}$ lysozyme $/ \mathrm{mL}$. The sample was incubated at $37^{\circ} \mathrm{C}$ for $30 \mathrm{~min}$ and then $30 \mu \mathrm{L}$ of $30 \%(\mathrm{w} / \mathrm{v})$ sodium $\mathrm{N}$ lauroyl-sarcosine (Sarcosyl) was added to it, incubated for $20 \mathrm{~min}$ at $65^{\circ} \mathrm{C}$, followed by incubation for $5 \mathrm{~min}$ at $4^{\circ} \mathrm{C}$. Purification of DNA with phenol/chloroform/isoamylalcohol (25:24:1) was followed by precipitation with ethanol. DNA concentration was $64.3 \mathrm{ng} / \mu \mathrm{l}$ as determined by Genios Tecan fluorometer, using the Quant-it Picogreen kit (Invitrogen).

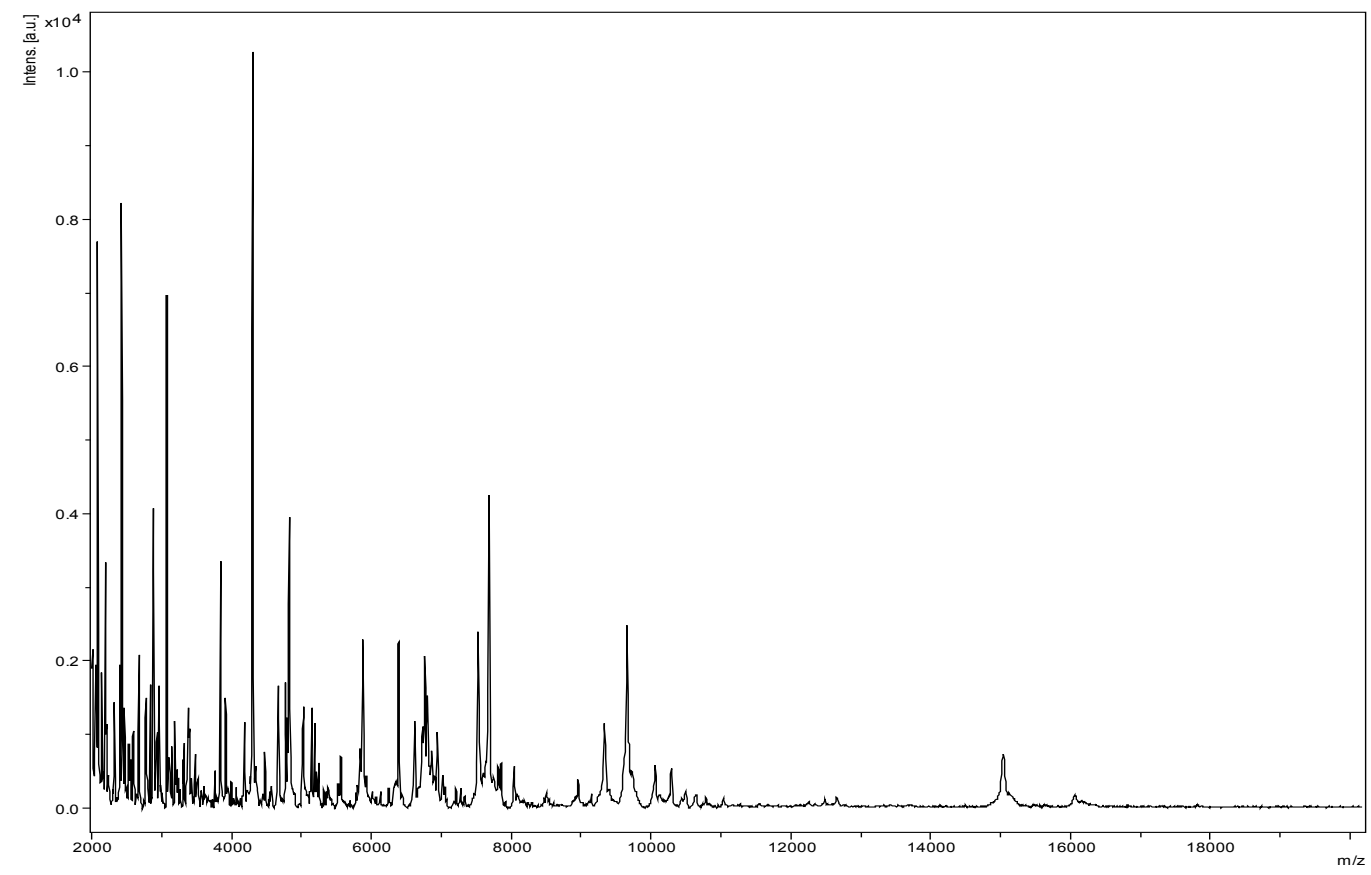

Figure 4. Reference mass spectrum from B. massilioanorexius strain AP8. Spectra from 12 individual colonies were compared and a reference spectrum was generated. 


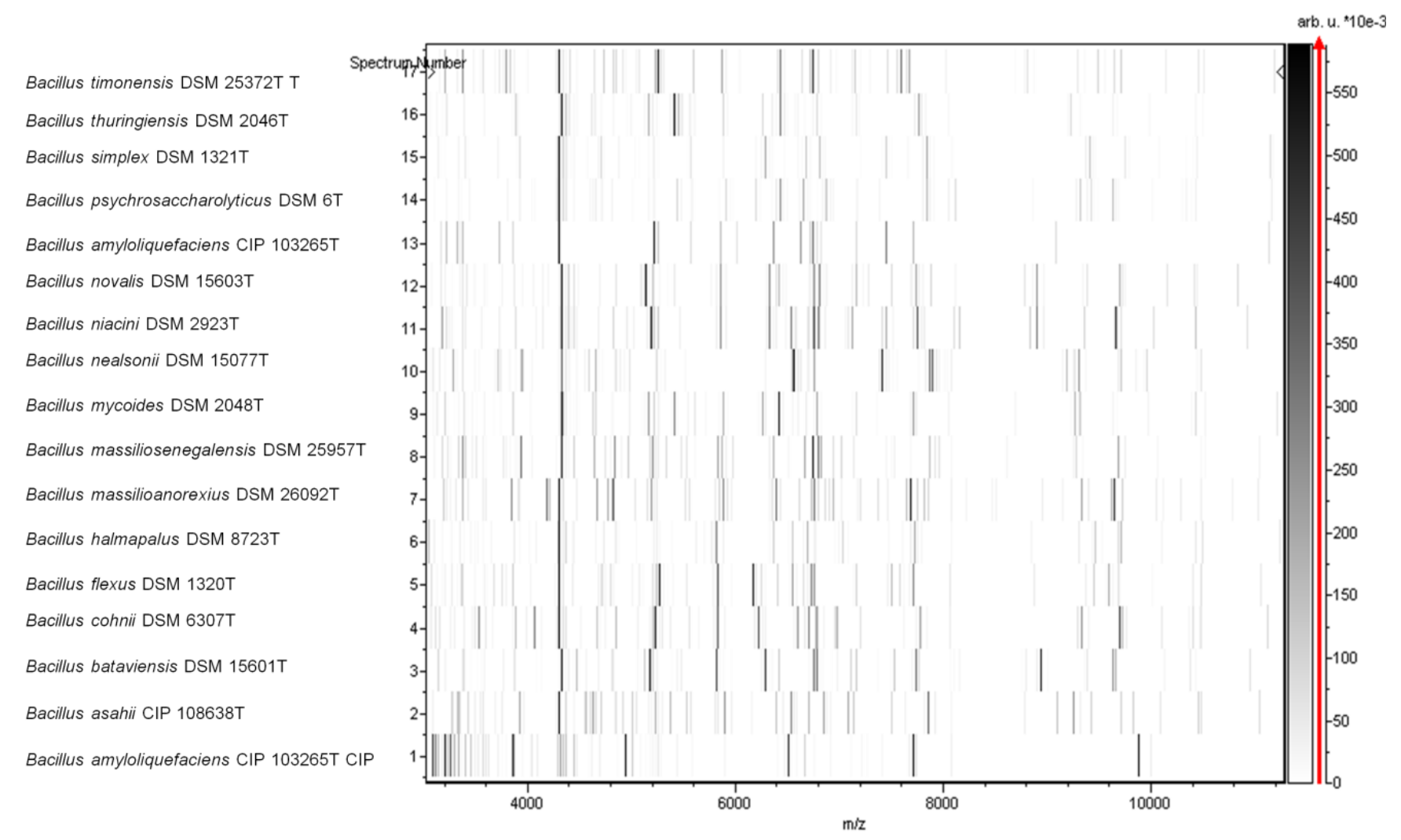

Figure 5. Gel view comparing B. massilioanorexius sp. nov strain $A P 8^{\top}$ and other Bacillus species. The gel view displays the raw spectra of loaded spectrum files arranged in a pseudo-gel like look. The $x$-axis records the $\mathrm{m} / \mathrm{z}$ value. The left $y$-axis displays the running spectrum number originating from subsequent spectra loading. The peak intensity is expressed by a Gray scale scheme code. The color bar and the right y-axis indicate the relation between the color a peak is displayed with and the peak intensity in arbitrary units. Displayed species are indicated on the left.

\section{Genome sequencing and assembly}

A $3 \mathrm{~kb}$ paired-end sequencing strategy (Roche, Meylan, France) was used. Five $\mu \mathrm{g}$ of DNA were mechanically fragmented on the Covaris device (KBioScience-LGC Genomics, Middlesex, UK) through miniTUBE-Red with an enrichment size at 3-4kb. The DNA fragmentation was visualized through the Agilent 2100 BioAnalyzer on a DNA labchip 7500 with an optimal size of $2.95 \mathrm{~kb}$. The library was constructed according to the 454 GS FLX Titanium paired-end protocol. Circularization and nebulization were performed which generated a pattern of 553 bp optimal size. PCR amplification was performed for 17 cycles followed by double size selection. The single stranded paired-end library was quantified using Quant-it Ribogreen kit (Invitrogen) with Genios Tecan fluorometer that yielded concentration of $556 \mathrm{pg} / \mu \mathrm{L}$. The library concentration equivalence was calculated as $1.82 \mathrm{E}+09$ molecules/ $\mu \mathrm{L}$. The library was stored at $20^{\circ} \mathrm{C}$ until further use.

The shotgun library was clonally amplified with $5 \mathrm{cpb}$ in 4 emPCR reactions and the $3 \mathrm{~kb}$ paired end library was amplified with lower cpb in 4 emPCR reactions at $1 \mathrm{cpb}$ and $2 \mathrm{emPCR}$ at $0.5 \mathrm{cpb}$ with the GS Titanium SV emPCR Kit (Lib-L) v2 (Roche). The yield of the shotgun emPCR reactions was 16.9 and $5.62 \%$ respectively for the two kinds of paired-end emPCR reactions according to the quality expected (range of 5 to 20\%) from the Roche procedure. Two libraries were loaded on the GS Titanium PicoTiterPlates (PTP Kit 70x75, Roche) and pyrosequenced with the GS Titanium Sequencing Kit XLR70 and the GS FLX Titanium sequencer (Roche). The run was performed overnight and analyzed on the cluster through the gsRunBrowser and Newbler assembler (Roche). A total of 410,883 passed filter wells were obtained and generated $144.49 \mathrm{Mb}$ with a length average of $344 \mathrm{bp}$. The passed filter sequences were assembled Using Newbler with $90 \%$ identity and 40 bp as overlap. The final assembly identified 20 scaffolds and 120 contigs and generated a genome size of $4.61 \mathrm{Mb}$ which corresponds to a coverage of $31.34 \times$ genome equivalent. 


\section{Genome annotation}

Open Reading Frames (ORFs) were predicted using Prodigal [49] with default parameters but the predicted ORFs were excluded if they were spanning a sequencing gap region. The predicted bacterial protein sequences were searched against the GenBank database [50] and the Clusters of Orthologous Groups (COG) databases using BLASTP. The tRNAScanSE tool [51] was used to find tRNA genes, whereas ribosomal RNAs were found by using RNAmmer [52] and BLASTn against the GenBank database. Lipoprotein signal peptides and the number of transmembrane helices were predicted using SignalP [53] and TMHMM [54] respectively. ORFans were identified if their BLASTP $E$-value was lower than $1 \mathrm{e}^{-03}$ for alignment length greater than 80 amino acids. If alignment lengths were smaller than 80 amino acids, we used an $E$-value of $1 \mathrm{e}^{-05}$. Such parameter thresholds have already been used in previous works to define ORFans. Ortholog sets composed of one gene from each of six genomes (B. massilioanorexius strain $\mathrm{AP}^{\mathrm{T}}, \quad B$. timonensis strain DSM 25372 (GenBank accession number CAET00000000), B. amyloliquefaciens strain FZB42 (GenBank accession number NC_009725), B. massiliosenegalensis strain JC6 $^{\mathrm{T}}$ (GenBank accession number CAHJ00000000), B. mycoides strain DSM 2048 (GenBank accession number CM000742) and B. thuringiensis strain
BMB171 (GenBank accession number CP001903),) were identified using the Proteinortho software (version 1.4) [55] using a 30\% protein identity and $1 \mathrm{e}^{-05} E$-value. The average percentage of nucleotide sequence identity between corresponding orthologous sets were determined using the NeedlemanWunsch algorithm global alignment technique. Artemis [56] was used for data management and DNA Plotter [57] was used for visualization of genomic features. Mauve alignment tool was used for multiple genomic sequence alignment and visualization [58].

\section{Genome properties}

The genome of $B$. massiliensis strain AP8 $^{\mathrm{T}}$ is $4,616,135$ bp long ( 1 chromosome, but no plasmid) with a $34.10 \% \mathrm{G}+\mathrm{C}$ content (Figure 6 and Table 4). Of the 4,519 predicted genes, 4,432 were protein-coding genes, and 87 were RNAs. Eight rRNA genes (one 16S rRNA, one 23S rRNA and six 5S rRNA) and 79 predicted tRNA genes were identified in the genome. A total of 3,290 genes $(72.80 \%)$ were assigned a putative function. Three hundred fifty-four genes were identified as ORFans (7.98\%). The remaining genes were annotated as hypothetical proteins. The properties and the statistics of the genome are summarized in Table 4 and Table 5. The distribution of genes into COGs functional categories is presented in Table 5.

Table 3. Project information

\begin{tabular}{lll}
\hline MIGS ID & Property & Term \\
\hline MIGS-31 & Finishing quality & High-quality draft \\
MIGS-28 & Libraries used & One 454 paired end 3-kb library \\
MIGS-29 & Sequencing platforms & 454 GS FLX Titanium \\
MIGS-31.2 & Fold coverage & $31.34 \times$ \\
MIGS-30 & Assemblers & Newbler version 2.5.3 \\
MIGS-32 & Gene calling method & Prodigal \\
& Genbank ID & CAPG00000000 \\
& Genbank Date of Release & November 28, 2012 \\
& Gold ID & Gi20708 \\
& Project relevance & Study of the human gut microbiome \\
\hline
\end{tabular}




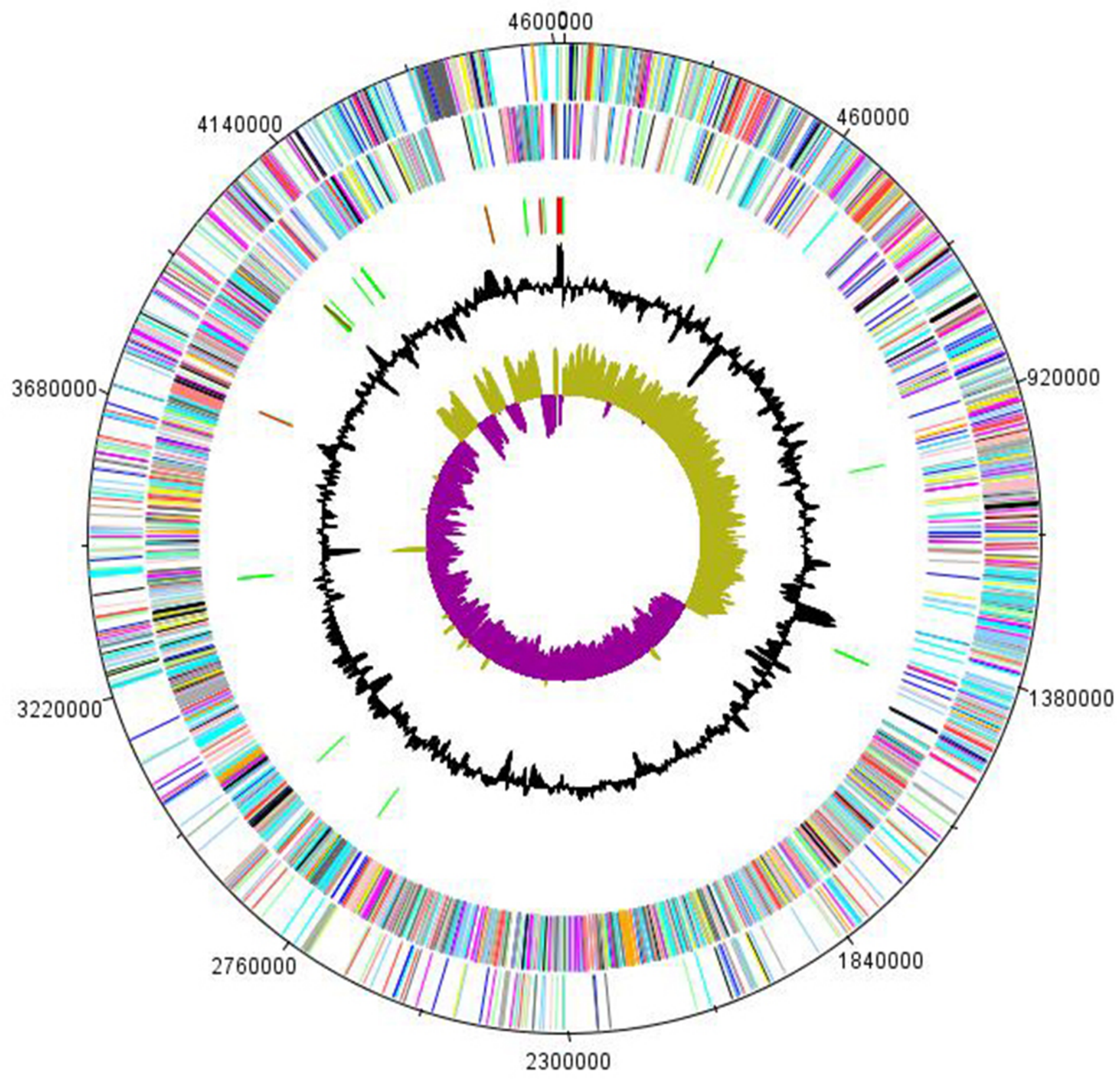

Figure 6. Graphical circular map of the chromosome. From the outside in, the outer two circles show open reading frames oriented in the forward and reverse directions (colored by COG categories), respectively. The third circle shows the rRNA gene operon (red) and tRNA genes (green). The fourth circle shows the $\mathrm{G}+\mathrm{C} \%$ content plot. The inner-most circle shows GC skew, purple and olive indicating negative and positive values, respectively. 
Table 4. Nucleotide content and gene count levels of the genome

\begin{tabular}{lrr}
\hline Attribute & Value & \% of total \\
\hline Genome size (bp) & $4,616,135$ & \\
DNA coding region (bp) & $3,750,534$ & 81.24 \\
DNA G+C content (bp) & $1,574,102$ & 34.10 \\
Number of replicons & 1 & \\
Extrachromosomal elements & 0 & \\
Total genes & 4,519 & 100 \\
RNA genes & 87 & 1.92 \\
rRNA operons & 1 & \\
Protein-coding genes & 4,432 & 98.07 \\
Genes with function prediction & 3,524 & 77.98 \\
Genes assigned to COGs & 3,290 & 72.80 \\
Protein coding genes assigned Pfam domains & 3,807 & 84.24 \\
Genes with peptide signals & 270 & 5.97 \\
Genes with transmembrane helices & 1,241 & 27.46 \\
CRISPR repeats & 2 & \\
\hline
\end{tabular}

a The total is based on either the size of the genome in base pairs or the total number of protein coding genes in the annotated genome

Table 5. Number of genes associated with the 25 general COG functional categories

\begin{tabular}{crrl}
\hline Code & Value & \%age $^{\mathbf{a}}$ & Description \\
\hline J & 171 & 3.86 & Translation \\
A & 0 & 0 & RNA processing and modification \\
K & 335 & 7.56 & Transcription \\
L & 200 & 4.51 & Replication, recombination and repair \\
B & 1 & 0.02 & Chromatin structure and dynamics \\
D & 37 & 0.83 & Cell cycle control, mitosis and meiosis \\
Y & 0 & 0 & Nuclear structure \\
V & 76 & 1.71 & Defense mechanisms \\
T & 212 & 4.78 & Signal transduction mechanisms \\
M & 147 & 3.32 & Cell wall/membrane biogenesis \\
N & 70 & 1.58 & Cell motility \\
Z & 0 & 0 & Cytoskeleton \\
W & 0 & 0 & Extracellular structures \\
U & 48 & 1.08 & Intracellular trafficking and secretion \\
O & 121 & 2.73 & Posttranslational modification, protein turnover, chaperones \\
C & 245 & 5.53 & Energy production and conversion \\
G & 221 & 4.99 & Carbohydrate transport and metabolism \\
E & 405 & 9.14 & Amino acid transport and metabolism \\
F & 98 & 2.21 & Nucleotide transport and metabolism \\
H & 135 & 3.05 & Coenzyme transport and metabolism \\
I & 136 & 3.07 & Lipid transport and metabolism \\
P & 258 & 5.82 & Inorganic ion transport and metabolism \\
Q & 81 & 1.83 & Secondary metabolites biosynthesis, transport and catabolism \\
R & 527 & 11.89 & General function prediction only \\
S & 349 & 7.87 & Function unknown \\
- & 1,142 & 25.77 & Not in COGs \\
\hline & & & \\
\hline
\end{tabular}

${ }^{a}$ The total is based on the total number of protein coding genes in the annotated genome. 


\section{Comparison with other Bacillus species genomes}

Here, we compared the genome of $B$. massilioanorexius strain AP8T, $B$. timonensis strain DSM 25372, B. amyloliquefaciens strain FZB42, B. massiliosenegalensis strain JC6 ${ }^{\mathrm{T}}$, $B$. mycoides strain DSM 2048 and B. thuringiensis strain BMB171. The draft genome of $B$. massilioanorexius is larger in size than that of B. amyloliquefaciens (4.6 vs 3.9 $\mathrm{Mb}$, respectively), similar in size than that of $B$. timonensis (4.6 Mb) and smaller in size than those of $B$. massiliosenegalensis, B. mycoides and $B$. thuringiensis $(4.9,5.5$ and $5.6 \mathrm{Mb}$, respectively). The $\mathrm{G}+\mathrm{C}$ content of $B$. massilioanorexius is lower than those of $B$. massiliosenegalensis, $B$. timonensis, $B$. amyloliquefaciens, $B$. mycoides and $B$. thuringiensis $(34.10,37.60,37.30,46.48,35.21$ and $35.18 \%$, respectively). The gene content of $B$. massilioanorexius is larger than that of $B$. amyloliquefaciens $(4,519$ and 3,814, respectively) and fewer than those of B. massiliosenegalensis, $B$. timonensis, B. mycoides and B. thuringiensis $(4,997$, $4,684,5,747$ and 5,495, respectively). The ratio of genes per $\mathrm{MB}$ of $B$. massilioanorexius is greater than that of $B$. amyloliquefaciens (982 and 978, respectively), comparable to that of $B$. thuringiensis (982) and smaller to those of $B$. massiliosenegalensis, $B$. timonensis and $B$. mycoides $(1,019,1,018$ and 1,044, respectively). However, the distribution of genes into COG categories was not entirely similar in all the three compared genomes (Figure 7). The nucleotide sequence identity ranged from 66.09 to $83.69 \%$ among Bacillus species, and from 66.09 to $70.10 \%$ between $B$. massilioanorexius and other Bacillus species, thus confirming its new species status. Table 6 summarizes the numbers of orthologous genes and the average percentage of nucleotide sequence identity between the different genomes studied.

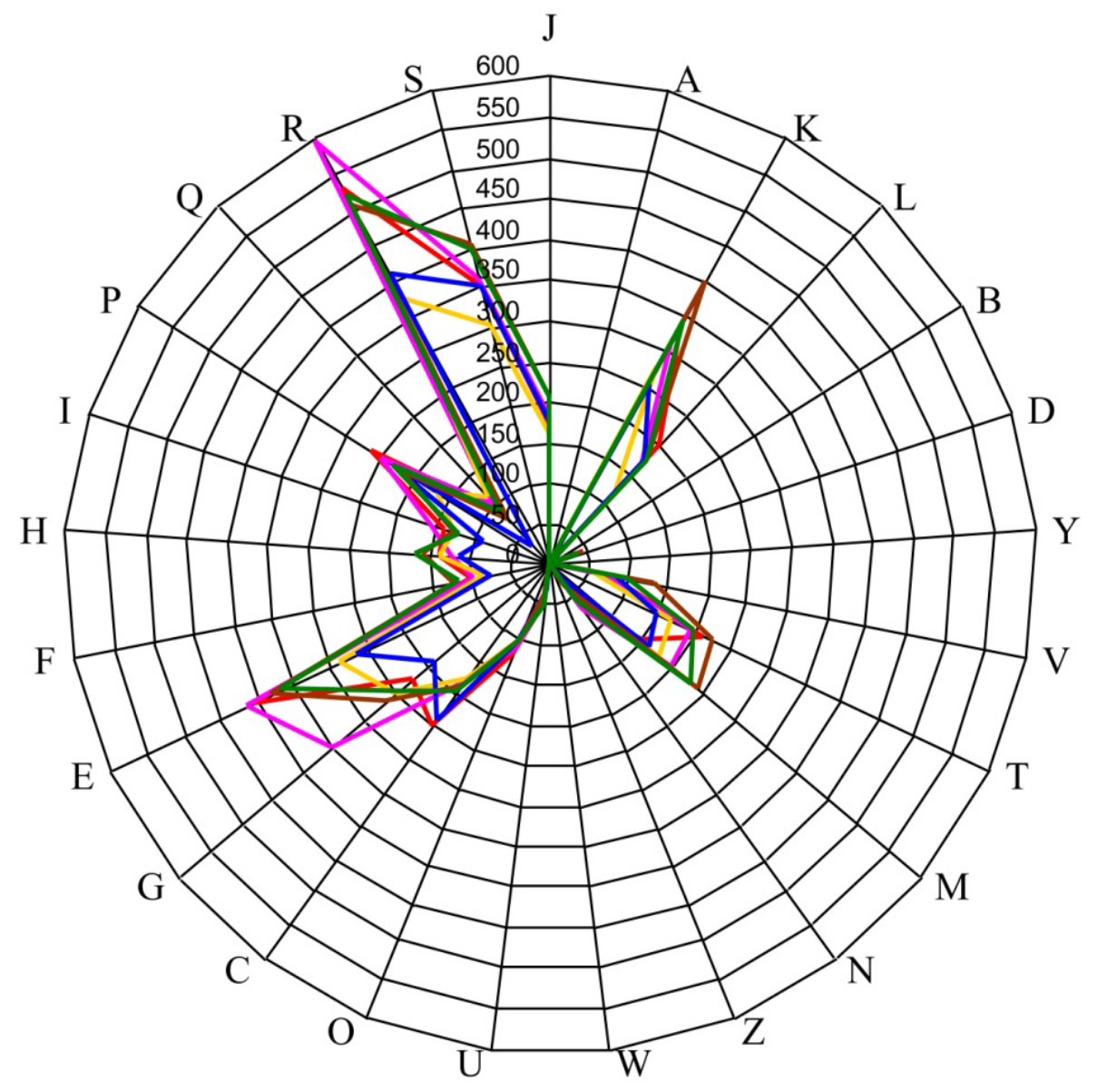

Figure 7. Distribution of functional classes of predicted genes in $B$. massilioanorexius (red), B. massiliosenegalensis (blue), B. timonensis (pink), B. amyloliquefaciens (yellow), B. mycoides (brown) and B. thuringiensis (green) chromosomes according to the clusters of orthologous groups of proteins. 
Table 6. Orthologous gene comparison and average nucleotide identity of Bacillus species B. massilioanorexius ${ }^{1}$ with B. massiliosenegalensis ${ }^{2}$; B. timonensis ${ }^{3}$, B. thuringiensis ${ }^{4}$; B. mycoides ${ }^{5}$; B. amyloliquefaciens ${ }^{6+}$.

\begin{tabular}{lrrrrrr}
\hline & massilioanorexius & $\begin{array}{r}\boldsymbol{B} \text { massiliosenegalensis } \\
\text { timonensis }\end{array}$ & $\begin{array}{r}\boldsymbol{B} \text { thuringiensis } \\
\text { timycoides }\end{array}$ & $\begin{array}{r}\boldsymbol{B} . \\
\text { amyloliquefaciens }\end{array}$ \\
\hline B. massilioanorexius & $\mathbf{4 , 4 3 2}$ & 1,897 & 1,864 & 1,887 & 1,794 & 1,709 \\
B. massiliosenegalensis & 70.10 & $\mathbf{4 , 8 9 5}$ & 1,965 & 1,863 & 1,765 & 1,755 \\
B. timonensis & 69.84 & 70.33 & $\mathbf{4 , 6 1 0}$ & 1,864 & 1,762 & 1,742 \\
B. thuringiensis & 69.35 & 68.88 & 69.31 & $\mathbf{6 , 2 4 3}$ & 2,210 & 1,832 \\
B. mycoides & 69.41 & 69.11 & 69.41 & 83.69 & $\mathbf{5 , 8 8 5}$ & 1,719 \\
B. amyloliquefaciens & 66.09 & 67.02 & 67.12 & 66.35 & 66.57 & $\mathbf{3 , 8 2 3}$ \\
\hline
\end{tabular}

${ }^{+}$Upper right, numbers of orthologous genes; lower left, mean nucleotide identities of orthologous genes. Bold numbers indicate the numbers of genes or each genome. ${ }^{1}$ Genbank accession number CAPG00000000, ${ }^{2}$ CAHJ00000000, ${ }^{3} \mathrm{CAET} 00000000,{ }^{4} \mathrm{CP} 001903,{ }^{5} \mathrm{CM} 000742,{ }^{6} \mathrm{NC} \_009725$

\section{Conclusion}

On the basis of phenotypic, phylogenetic and genomic analyses, we formally propose the creation of Bacillus massilioanorexius sp. nov. that contains the strain AP8T. The strain has been found in France.

\section{Description of Bacillus massilioanorexius sp. nov.} Bacillus massilioanorexius (ma.si.li.o.a.no.rex'i.us. L. masc. adj. massilioanorexius, combination of Massilia, the Latin name of Marseille, France, where the type strain was isolated, and anorexia, the disease presented by the patient from whom the strain was cultivated).

Colonies were $3 \mathrm{~mm}$ in diameter and $0.5 \mathrm{~mm}$ in thickness, gray in color with a coarse appearance on blood-enriched Columbia agar. Cells are rodshaped with a mean diameter of $0.77 \mu \mathrm{m}$. Optimal growth occurs aerobically, weak growth was observed under anaerobic conditions. Growth occurs between 25 and $45^{\circ} \mathrm{C}$, with optimal growth ob-

\section{Acknowledgements}

The authors thank the Xegen Company (www.xegen.fr) for automating the genomic annotation process. This

\section{References}

1. Lagier JC, Armougom F, Million M, Hugon P, Pagnier I, Robert C, Bittar F, Fournous G, Gimenez G, Maraninchi M, et al. Microbial culturomics: paradigm shift in the human gut microbiome study. Clin Microbiol Infect 2012; 18:1185-1193. PubMed served at $37^{\circ} \mathrm{C}$. Cells stain Gram-positive, are nonendospore forming and are motile. Cells are Grampositive, catalase-positive, oxidase-positive. Dglucose, D-fructose, D-saccharose, D-trehalose, ribose, mannitol, mannose were used as carbon source. Positive reactions were observed for tryptophane deaminase, acetoin and gelatinase production. Weak reactions were obtained for Lrhamnose, esculine, salicine, D-cellobiose and gentiobiose. Cells are susceptible to amoxicillin, rifampicin, ciprofloxacin, gentamicin, doxycycline and vancomycin but resistant to trimethoprim/sulfamethoxazole and metronidazole.

The $\mathrm{G}+\mathrm{C}$ content of the genome is $34.10 \%$. The 16S rRNA and genome sequences are deposited in GenBank under accession numbers JX101689 and CAPG00000000, respectively. The type strain

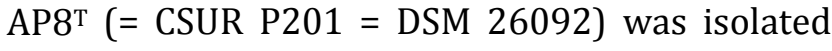
from the fecal flora of a female suffering from anorexia nervosa in Marseille, France.

study was funded by the Mediterranée-Infection Foundation.

2. Dubourg G, Lagier JC, Armougom F, Robert C, Hamad I, Brouqui P. The gut microbiota of a patient with resistant tuberculosis is more comprehensively studied by culturomics than by metagenomics. Eur J Clin Microbiol Infect Dis 2013; 32:637-645. PubMed http://dx.doi.org/10.1007/s10096-012-1787-3 
3. Pfleiderer A, Lagier JC, Armougom F, Robert C, Vialettes B, Raoult D. Culturomics identified 11 new bacterial species from a single anorexia nervosa stool sample. [Epub ahead of print]. Eur J Clin Microbiol Infect Dis 2013. PubMed http://dx.doi.org/10.1007/s10096-013-1900-2

4. Tindall BJ, Rossello-Mora R, Busse HJ, Ludwig W, Kampfer P. Notes on the characterization of prokaryote strains for taxonomic purposes. Int I Syst Evol Microbiol 2010; 60:249-266. PubMed http://dx.doi.org/10.1099/ijs.0.016949-0

5. Genome Online Database. http://www.genomesonline.org/cgibin/GOLD/index.cgi

6. The Microbial Earth Project. http://www.microbial-earth.org

7. Kokcha S, Mishra AK, Lagier JC, Million M, Leroy Q, Raoult D, Fournier PE. Non-contiguous finished genome sequence and description of Bacillus timonensis sp. nov. Stand Genomic Sci 2012; 6:346-355. PubMed http://dx.doi.org/10.4056/sigs.2776064

8. Lagier JC, El Karkouri K, Nguyen TT, Armougom F, Raoult D, Fournier PE. Non-contiguous finished genome sequence and description of Anaerococcus senegalensis sp. nov. Stand Genomic Sci 2012; 6:116-125. PubMed http://dx.doi.org/10.4056/sigs.2415480

9. Mishra AK, Gimenez G, Lagier JC, Robert C, Raoult D, Fournier PE. Non-contiguous finished genome sequence and description of Alistipes senegalensis sp. nov. Stand Genomic Sci 2012; 6:304-314. http://dx.doi.org/10.4056/sigs.2625821

10. Lagier JC, Armougom F, Mishra AK, Ngyuen TT, Raoult D, Fournier PE. Non-contiguous finished genome sequence and description of Alistipes timonensis sp. nov. Stand Genomic Sci 2012; 6:315-324. PubMed

11. Mishra AK, Lagier JC, Robert C, Raoult D, Fournier PE. Non-contiguous finished genome sequence and description of Clostridium senegalense sp. nov. Stand Genomic Sci 2012; 6:386-395. PubMed

12. Mishra AK, Lagier JC, Robert C, Raoult D, Fournier PE. Non-contiguous finished genome sequence and description of Peptoniphilus timonensis sp. nov. Stand Genomic Sci 2012; 7:111. PubMed http://dx.doi.org/10.4056/sigs.2956294
13. Mishra AK, Lagier JC, Rivet R, Raoult D, Fournier PE. Non-contiguous finished genome sequence and description of Paenibacillus senegalensis sp. nov. Stand Genomic Sci 2012; 7:70-81. PubMed

14. Lagier JC, Gimenez G, Robert C, Raoult D, Fournier PE. Non-contiguous finished genome sequence and description of Herbaspirillum massiliense sp. nov. Stand Genomic Sci 2012; 7:200-209. PubMed

15. Roux V, El Karkouri K, Lagier JC, Robert C, Raoult D. Non-contiguous finished genome sequence and description of Kurthia massiliensis sp. nov. Stand Genomic Sci 2012; 7:221-232. PubMed http://dx.doi.org/10.4056/sigs.3206554

16. Kokcha S, Ramasamy D, Lagier JC, Robert C, Raoult D, Fournier PE. Non-contiguous finished genome sequence and description of Brevibacterium senegalense sp. nov. Stand Genomic Sci 2012; 7:233-245. PubMed http://dx.doi.org/10.4056/sigs.3256677

17. Ramasamy D, Kokcha S, Lagier JC, N'Guyen TT, Raoult D, Fournier PE. Non-contiguous finished genome sequence and description of Aeromicrobium massilense sp. nov. Stand Genomic Sci 2012; 7:246-257. PubMed http://dx.doi.org/10.4056/sigs.3306717

18. Lagier JC, Ramasamy D, Rivet R, Raoult D, Fournier PE. Non-contiguous finished genome sequence and description of Cellulomonas massiliensis sp. nov. Stand Genomic Sci 2012; 7:258-270. PubMed http://dx.doi.org/10.4056/sigs.3316719

19. Lagier JC, El Karkouri K, Rivet R, Couderc C, Raoult D, Fournier PE. Non-contiguous finished genome sequence and description of Senegalemassilia anaerobia sp. nov. Stand Genomic Sci 2013; 7:343-356. http://dx.doi.org/10.4056/sigs.3246665

20. Mishra AK, Hugon P, Lagier JC, Nguyen TT, Robert C, Couderc C, Raoult D, Fournier PE. Noncontiguous finished genome sequence and description of Peptoniphilus obesi sp. nov. Stand Genomic Sci 2013; 7:357-369. http://dx.doi.org/10.4056/sigs.32766871

21. Mishra AK, Lagier JC, Nguyen TT, Raoult D, Fournier PE. Non-contiguous finished genome sequence and description of Peptoniphilus senegalensis sp. nov. Stand Genomic Sci 2013; 7:370-381. http://dx.doi.org/10.4056/sigs.3366764

22. Lagier JC, El Karkouri K, Mishra AK, Robert C, Raoult D, Fournier PE. Non-contiguous finished 
genome sequence and description of Enterobacter massiliensis sp. nov. Stand Genomic Sci 2013; 7:399-412. http://dx.doi.org/10.4056/sigs.3396830

23. Hugon P, Ramasamy D, Lagier JC, Rivet R, Couderc C, Raoult D, Fournier PE. Noncontiguous finished genome sequence and description of Alistipes obesi sp. nov. Stand Genomic Sci 2013; 7:427-439. http://dx.doi.org/10.4056/sigs.3336746

24. Mishra AK, Hugon P, Robert C, Couderc C, Raoult D, Fournier PE. Non-contiguous finished genome sequence and description of Peptoniphilus grossensis sp. nov. Stand Genomic Sci 2012; 7:320-330. PubMed

25. Mishra AK, Hugon P, Lagier JC, Nguyen TT, Couderc C, Raoult D, Fournier PE. Non contiguous-finished genome sequence and description of Enorma massiliensis gen. nov., sp. nov., a new member of the Family Coriobacteriaceae. Stand Genomic Sci 2013; 8:290-305. http://dx.doi.org/10.4056/sigs.3426906

26. Ramasamy D, Lagier JC, Gorlas A, Raoult D, Fournier PE. Non contiguous-finished genome sequence and description of Bacillus massiliosenegalensis sp. nov. Stand Genomic Sci 2013; 8:336-351.

http://dx.doi.org/10.4056/sigs.3567059

27. Ramasamy D, Lagier JC, Nguyen TT, Raoult D, Fournier PE. Non contiguous-finished genome sequence and description of of Dielma fastidiosa gen. nov., sp. nov., a new member of the Family Erysipelotrichaceae. Stand Genomic Sci 2013; 8:336-351. http://dx.doi.org/10.4056/sigs.3567059

28. Mishra AK, Lagier JC, Robert C, Raoult D, Fournier PE. Genome sequence and description of Timonella senegalensis gen. nov., sp. nov., a new member of the suborder Micrococcinae. Stand Genomic Sci 2013; 8:318-335. http://dx.doi.org/10.4056/sigs.3476977

29. Cohn F. Untersuchungen über Bakterien. Beitrage zur Biologie der Pflanzen Heft 1872; 1:127-224.

30. Mathews WC, Caperna J, Toerner JG, Barber RE, Morgenstern $\mathrm{H}$. Neutropenia is a risk factor for gram-negative bacillus bacteremia in human immunodeficiency virus-infected patients: results of a nested case-control study. Am / Epidemiol 1998; 48:1175-1183.25.

31. Logan NA. Bacillus species of medical and veterinary importance. J Med Microbiol 1988; 25:157-
165. PubMed

http://dx.doi.org/10.1099/00222615-25-3-157

32. Jernigan JA, Stephens DS, Ashford DA, Omenaca C, Topiel MS, Galbraith M, Tapper M, Fisk TL, Zaki S, Popovic T, et al. Bioterrorism-related inhalational anthrax: the first 10 cases reported in the United States. Emerg Infect Dis 2001; 7:933-944. PubMed http://dx.doi.org/10.3201/eid0706.010604

33. Bottone EJ. Bacillus cereus, a volatile human pathogen. Clin Microbiol Rev 2010; 23:382-398. PubMed http://dx.doi.org/10.1128/CMR.00073$\underline{09}$

34. Purswani J, Pozo C, Rodriguez-Diaz M, Gonzalez-Lopez J. Selection and identification of bacterial strains with methyl-tert-butyl ether, ethyl-tertbutyl ether, and tert-amyl methyl ether degrading capacities. Environ Toxicol Chem 2008; 27:22962303. PubMed http://dx.doi.org/10.1897/08096.1

35. Stackebrandt E, Ebers J. Taxonomic parameters revisited: tarnished gold standards. Microbiol Today 2006; 33:152-155.

36. Woese CR, Kandler O, Wheelis ML. Towards a natural system of organisms: proposal for the domains Archae, Bacteria, and Eukarya. Proc Natl Acad Sci USA 1990; 87:4576-4579. PubMed http://dx.doi.org/10.1073/pnas.87.12.4576

37. Gibbons NE, Murray RGE. Proposals concerning the Higher Taxa of the Bacteria. Int J Syst Bacteriol 1978; 28:1-6. http://dx.doi.org/10.1099/00207713-28-1-1

38. Garrity GM, Holt JG. The Road Map to the Manual. In: Garrity GM, Boone DR, Castenholz RW (eds), Bergey's Manual of Systematic Bacteriology, Second Edition, Volume 1, Springer, New York, 2001, p. 119-169.

39. Murray RGE. The Higher Taxa, or, a Place for Everything...? In: Holt JG (ed), Bergey's Manual of Systematic Bacteriology, First Edition, Volume 1, The Williams and Wilkins Co., Baltimore, 1984, p. 31-34.

40. List Editor. List of new names and new combinations previously effectively, but not validly, published. List no. 132. Int I Syst Evol Microbiol 2010; 60:469-472. http://dx.doi.org/10.1099/ijs.0.022855-0

41. Ludwig W, Schleifer KH, Whitman WB. Class I. Bacilli class nov. In: De Vos P, Garrity G, Jones D, Krieg NR, Ludwig W, Rainey FA, Schleifer KH, Whitman WB (eds), Bergey's Manual of Systemat- 
ic Bacteriology, Second Edition, Volume 3, Springer-Verlag, New York, 2009, p. 19-20.

42. Skerman VBD, Sneath PHA. Approved list of bacterial names. Int J Syst Bact 1980; 30:225-420. http://dx.doi.org/10.1099/00207713-30-1-225

43. Prévot AR. Dictionnaire des bactéries pathogens. In: Hauduroy P, Ehringer G, Guillot G, Magrou J, Prevot AR, Rosset, Urbain A (eds). Paris, Masson, 1953, p.1-692.

44. Fischer A. Untersuchungen über bakterien. Jahrbücher für Wissenschaftliche Botanik 1895; 27:1-163.

45. Gibson T, Gordon RE. Genus I. Bacillus Cohn 1872, 174; Nom. gen. cons. Nomencl. Comm. Intern. Soc. Microbiol. 1937, 28; Opin. A. Jud. Comm. 1955, 39. In: Buchanan RE, Gibbons NE (eds), Bergey's Manual of Determinative Bacteriology, Eighth Edition, The Williams and Wilkins Co., Baltimore, 1974, p. 529-550.

46. Ashburner M, Ball CA, Blake JA, Botstein D, Butler $\mathrm{H}$, Cherry JM, Davis AP, Dolinski K, Dwight SS, Eppig JT. Gene ontology: tool for the unification of biology. The Gene Ontology Consortium. Nat Genet 2000; 25:25-29. PubMed http://dx.doi.org/10.1038/75556

47. Seng P, Drancourt M, Gouriet F, La Scola B, Fournier PE, Rolain JM, Raoult D. Ongoing revolution in bacteriology: routine identification of bacteria by matrix-assisted laser desorption ionization time-of-flight mass spectrometry. Clin Infect Dis 2009; 49:543-551. PubMed http://dx.doi.org/10.1086/600885

48. Field D, Garrity G, Gray T, Morrison N, Selengut J, Sterk P, Tatusova T, Thomson N, Allen MJ, Angiuoli SV, et al. The minimum information about a genome sequence (MIGS) specification. Nat Biotechnol 2008; 26:541-547. PubMed http://dx.doi.org/10.1038/nbt1360

49. Prodigal. http://prodigal.ornl.gov

50. GenBank database. http://www.ncbi.nlm.nih.gov/genbank
51. Lowe TM, Eddy SR. tRNAscan-SE: a program for improved detection of transfer RNA genes in genomic sequence. Nucleic Acids Res 1997; 25:955-964. PubMed

52. Lagesen K, Hallin P, Rodland EA, Staerfeldt HH, Rognes T, Ussery DW. RNAmmer: consistent and rapid annotation of ribosomal RNA genes. Nucleic Acids Res 2007; 35:3100-3108. PubMed http://dx.doi.org/10.1093/nar/gkm160

53. Bendtsen JD, Nielsen H, von Heijne G, Brunak S. Improved prediction of signal peptides: SignalP 3.0. J Mol Biol 2004; 340:783-795. PubMed http://dx.doi.org/10.1016/j.jmb.2004.05.028

54. Krogh A, Larsson B, von Heijne G, Sonnhammer EL. Predicting transmembrane protein topology with a hidden Markov model: application to complete genomes. J Mol Biol 2001; 305:567580. PubMed http://dx.doi.org/10.1006/jmbi.2000.4315

55. Lechner M, Findeib S, Steiner L, Marz M, Stadler PF, Prohaska SJ. Proteinortho: Detection of (Co)orthologs in large-scale analysis. BMC Bioinformatics 2011; 12:124. PubMed http://dx.doi.org/10.1186/1471-2105-12-124

56. Rutherford K, Parkhill J, Crook J, Horsnell T, Rice $P$, Rajandream MA, Barrell B. Artemis: sequence visualization and annotation. Bioinformatics 2000; 16:944-945. PubMed http://dx.doi.org/10.1093/bioinformatics/16.10.94 $\underline{4}$

57. Carver T, Thomson N, Bleasby A, Berriman M, Parkhill J. DNAPlotter: circular and linear interactive genome visualization. Bioinformatics 2009; 25:119-120. PubMed http://dx.doi.org/10.1093/bioinformatics/btn578

58. Darling AC, Mau B, Blattner FR, Perna NT. Mauve: multiple alignment of conserved genomic sequence with rearrangements. Genome Res 2004; 14:1394-1403. PubMed http://dx.doi.org/10.1101/gr.2289704 